\title{
An Evaluation of Zoning as an Effective Urban Land Use Control and Administration Strategy in Enugu Metropolis, Enugu State, Nigeria
}

\author{
Ugonabo Celestine U. * Okafor, Johnbosco I. Igwe Chinelo P. \\ Department of Estate Management, NnamdiAzikiwe University, Awka
}

\begin{abstract}
The beauty of an urban city is efficient separation of different land uses so that it creates a pleasant environment for man's need. The government understands that land is a treasure; hence there are legislations on the use of land. In spite of all the legislations, there are still existing problems and inadequacies in various uses of land in Enugu metropolis. The study evaluates zoning as an effective urban land use control and administration strategy in Enugu metropolis. In order to achieve this aim, survey research design was adopted. Questionnaires were distributed and responses from the respondents were analyzed using statistical mean analysis and tables. Based on the findings, it was discovered that zoning is accorded the most effective urban land use control and administration strategy in Enugu metropolis, though not erasing the fact that there are other strategies for urban land use control and administration, applicable in Enugu metropolis. In view of the findings, the study recommends that zoning must be accorded its legal and proper place in urban land development and control.
\end{abstract}

Keywords: Zoning, Urban, Land-use, Control, Administration, Strategy

DOI: $10.7176 / \mathrm{JESD} / 11-16-13$

Publication date:August $31^{\text {st }} 2020$

\section{Introduction}

Land is required for various uses in both the urban and rural areas of the society. It is a major factor of production and a vital element in the socio-economic development of any country or society (FMH \& UD, 2006). Thus, as nations grow in size and rural areas become urban centres and urban centres become large metropolitan areas, there is always increased competition as well as demand for land for different purposes. This requires adequate planning and control to ensure harmonious development and functional efficiency of these uses. To achieve this fundamental and acceptable activity, layouts of various land uses such as residential, commercial, industrial, open spaces and recreational, circulation and institutional uses among others are undertaken to standardize and control physical development and ensure harmonious growth. Furthermore, as the population of the world becomes more urbanized and cities grow, urban planning becomes more critical (Smith and Engel, 2006). According to Oyesiku (1998), the forms and patterns of distribution of structures in general to promote the health, accessibility, convenience and harmonious land use in the environment are functions, to a considerable extent, of the rights and methods of dealing with land.

Land and its resources remain the basic element to the sustenance of the universe. The significance of land use in the physical, socio-political and economic growth in the development of cities cannot be overemphasized, hence, the intrinsic value of land is perceived through the various uses that land is committed.

Urban land is any land which falls within the geographical areas of an urbanized environment. Land in urban areas is limited in supply, relatively scarce and command high value. However, the nature and pattern of land use dynamics in an urban environment is complex and interdependent. Urban land is needed for quite a variety of uses. These can be for residential, commercial, industrial, recreational uses, etc. Without proper allocation of urban land for these uses, development will go ahead haphazardly without due consideration of the implications and the impact these developments have on the environment as well as the people living in the area. Different urban areas tend to have wide differences in land use pattern. Therefore, varying features such as topography, climatic conditions, tax and present social and religious customs, legislation and legal decision, demands for goods and services, policy of government in the supply of social amenities all provide frameworks for the development and land use of a place.

Most of our cities have grown in an uncontrolled and unmonitored manner. The existing system has failed to provide efficient urban land use administration. Planning for specific projects are not coordinated to meet fast growing population now and in the future. The system has failed to indicate land use pattern for population distribution. In Nigeria, most major cities like Lagos, Kaduna, Port Harcourt, Onitsha, Enugu, Aba and some other parts of Niger Delta region have developed with the conventional land use approach (Jiboye, 2005). This has generated diverse urban problems manifesting in the form of deterioration of cities into slums, pollution, congestion, unsanitary condition and epidemics. Nigerian cities are characterized by non-functioning infrastructural facilities, most poorly governed, intensively dotted with illegal structures, while physical growth and development of the cities had not been properly managed or controlled (Aluko, 2000). The rate of growth of 
Nigerian urban centres has given rise to the increasing problem of traffic congestion, overcrowding, deteriorating environmental qualities and general pressure on urban facilities.

Some parts of Enugu metropolis have grown in an uncontrolled and unmonitored manner, leading to various problems such as overcrowding, traffic congestion, environmental pollution, haphazard development as well as over-stretch of urban amenities. In some parts of the metropolis, these problems have precipitated into socioeconomic, socio-cultural and sanitary problems. Incompatible land uses have caused negative social and economic imbalance and environmental impacts. The rate of growth of the metropolis has given rise to increasing problem of slum, illegal structures, haphazard development, dysfunctional aspect of urban land use, and the prevalence of unauthorized structures in some parts of the metropolis.

\section{Concept of Urban Land Use Administration}

Land administration is the process whereby the resources of land are put to good effect (Eze \& Alozie, 2016). These processes include the determination of land rights and other attributes, their detailed documentation and the provision of relevant information for supporting land markets.

Mabogunje (2008) opines that effective administration of urban areas as regards real estate development can only be achieved through breaking away from present routine of urban administration to more development oriented urban administration. According to him, this can be achieved through conceptualizing urban administration as a vigorous planning in which physical layout of urban areas and land use zoning are seen as one part of a comprehensive effort. The importance of urban land use control and administration in the economic life of any nation notwithstanding, no government in any African country has ever given priority to urban land administration in her activities. However, time has come for government to device efficient administrative programs for the urban area, especially now that there is quest for industrial and technological growth, with a frightening concentration of population in most of the urban areas as evidenced in Enugu, Lagos, Port Harcourt, etc. These have given a sharp edge to the complexity of good urban land administration which calls not merely for government participation but for developers/the general public to be in the forefront of the battle.

\subsection{Concept of Land Use Control}

Land use control is essentially a public administration process that ensures the availability of sufficient land for necessary uses such as residential, commercial, recreational, transportations, etc and ensures equitable resolution of conflicts among and between land use categories. Land use controls are instituted to ensure that uses of land particularly in the urban areas conform to public interest. Land use control is generally imposed for the interest of the community. It ensures that the various land uses complement and not conflict each other. This goes a long way to enhance environmental and public safety.

The property market cannot wholly be relied upon to produce a rational and efficient land use system which accommodates all present legitimate needs for space for the citizens, while simultaneously accommodating the future needs of the society. It is almost impossible to achieve effective land use control in urban area without the means of controlling and administering use of land. Land use control can be achieved using the following tools; zoning, land subdivision regulations and building codes.

\subsubsection{Zoning as a tool for Land Use Control}

According to Lamar and Anika (2015), zoning is the process of dividing land in a municipality into zones (example, residential, industrial, etc) in which certain land uses are permitted or prohibited. In addition, the sizes, bulk, and replacement of buildings may be regulated. The type of zone determines whether planning permission for a given development is granted. Zoning may specify a variety of outright and conditional uses of land. It may also indicate the size and dimensions of land areas as well as the form and scale of buildings. These guidelines are set in order to guide urban growth and development, Gerald (2014).

Legally, a zoning plan is usually enacted as a by-law with the respective procedures. In some countries, for example, Canada or Germany, zoning plans must comply with upper-tier (regional, state, provincial) planning and policy statements. There are a great variety of zoning types, some of which focus on regulating building form and the relation of buildings to the street with mixed-uses, known as form-based, others with separating land uses, known as use-based or a combination thereof. Similar urban planning methods have dictated the use of various areas for particular purposes in many cities from ancient times.

According to Ratcliff (2018), zoning is the most common method of controlling land use over the world. $\mathrm{He}$ opined that zoning is the method by which development plans segregate parcels of land or areas of town as ascribes to them abroad classification of appropriate uses. The objectives of zoning regulation is to establish regulations for all essential uses of land and buildings and to ensure that each use is located in the most appropriate place. Zoning helps to exclude nuisance which tend to create blight in a particular zone. Over the years, zoning has been an accepted means of regulating the use of land 


\subsection{Development Control}

Development control is the power to control development by granting or refusing or attaching conditions to permission for it to take place (Nze, 1995). According to Osinbajo (2004) it is the way and manner in which land use or physical development of land is regulated. Common man's activities on land are agricultural, forestry, residential, commercial, industrial, etc. These activities compete for limited space in urban setting or in our cities. To avoid conflict and ensure compatibility among various land uses, the mechanism of control is very essential. Development control seeks to ensure the orderly arrangement and control of these activities in space. It is a guide through which land use is licensed for building and other purposes backed up by planned law (Alder, 2018). It ensures that there will be adequate light, ventilation, playground for children and space for relaxation and recreation. It also ensures that residential, commercial, industrial, institutional and agricultural areas are properly and carefully zoned to prevent conflict and promote harmonious inter-relationships (Memuna, 2015). Development control is aimed at checking the activities of real estate developers and land owners by ensuring that they do not develop their property as they like to the detriment of public interest.

\subsection{Government Development Control Measures Zoning:}

This means the division of land district having different regulations. Zoning is a form of governmental regulation providing for orderly social and economic development of a community. Adeniyi (1999) opines that zoning is the process of classifying land within a government entity into areas and district being generally referred to as "ZONES" by legislation. This tool is most frequently employed to regulate the use of land. Zoning commonly includes regulations on the kinds of activities which will be acceptable on particular lots such as open space, residential, commercial or industrial.

Zoning gives teeth to planning agencies, commissioning board and planning authorities Kaltho (1985). Through zoning, compatible land uses are ensured as well as development.

\section{Subdivision Regulation:}

This involves the division of land into lots in order to prevent undesirable land use pattern, traffic congestion, insufficient open space etc. Subdivision regulation is a land use control measure and it is used to implement a community plan. Barlowe (1978) opined that without adequate land subdivision, there will be easy spread of slum condition and high public maintenance cost which can lead to blight in an area. The impact of subdivision regulation is more permanent than zoning, because once land is divided into lots and streets layouts, development pattern is set.

\section{Density Control Regulation:}

This is land use control measure used to ensure that all types of development conform to the number of building unit and number of habitable room per plot. This is to enhance space for air circulation, movement, landscaping and recreation.

\section{Building Code:}

This defines the way new structures are to be built and the materials to be used. It may be applied to be the maintenance and improvement of existing building, and this code provides for the minimum standards of building construction and the condition for human occupancy. It is concerned with such factors as lighting, ventilation, sanitation, plumbing, fire prevention and protection, minimum number of habitable rooms allowed, minimum building height, etc.

Environmental Impact Assessment (EIA):

This is used to ascertain the potential environmental, socio-economic and health effect of some proposed development projects within a particular area. It identifies measures to reduce the impact of some types of development and outline ways to improve the project's suitability in the area.

\subsection{Land Use Pattern Discernible In Enugu Metropolis}

In Enugu Metropolis the land uses are classified as:

I. Residential land use

II. Commercial land use

III. Recreational land use

IV. Industrial land use

V. Circulatory and land use

Residential Land Use: The residential space in Enugu is classified into high, medium, and low densities. Due to influence of sprawl, mixed densities exist. Planned and unplanned area sprang alongside Enugu metropolis as a result of a demand for residential accommodation. Many informal commercial streets like Kenyetta-Edozie street axis, Ogui road, Abakpa road, Chime Avenue, etc, could be spotted existing in the residential units. The unapproved attachment of illegal shops, indiscriminate creation of kiosks in the residential building constitutes a dysfunctional land use. This is very common in the high density areas such as Uwani, Awkunanaw, Ogbete, Achara 
Layout and Abakpa Nike. It is however the shanty (slums) that present the most visible evidence of spatial portions of Nigerian cities. The make shift structures appear overnight to become the abode of countless hundreds of squatters. Obiagu, Abakpa Nike and Ogbete are good examples of areas having make shift type of structures. Notably, the activities of the task force on environmental sanitation, works and housing have however helped to reduce the persistent growth of these illegal structures.

High Density Area: This constitutes about 70\% of the entire neighborhood in Enugu metropolis. The high density areas include Ogbete (Coal Camp), Ogui New Layout, Abakpa, Emene and Obiagu. Tenements buildings dominate in these areas. They constitute about $4-5 \%$ of the total housing stock in Enugu with a density of more than 700 persons per hectare..

Medium DensityArea: This contains about $28 \%$ of the entire population of Enugu (Enugu Master Plan, 1979). The medium density areas include; Achara Layout, New Haven, Mary Land and parts of Trans-Ekulu. The average density is about 300 - 400 persons per-hectare. The average household size is about 5 - 6 persons per household especially in Maryland. The population density is between 175 and 200 persons per hectare. Uwani has a mixed density containing both high and medium densities.

Low Density Area: This neighborhood contains about $2 \%$ of the urban population of Enugu. This includes G.R.A, parts of Trans-Ekulu, Independence Layout etc having relatively low density of between 18 and 60 persons per hectare and comprises semidetached duplexes, appreciable number of bungalows and blocks of flats. Commercial Land Use

Misuse of Enugu urban land that arose from commercial use is traceable to the unplanned mixture of commercial use of urban space and it is often seen as an aspect of disorderliness in Nigerian cities generally. Taking Okpara Avenue, Zik's Avenue and Ogui Road (the three main commercial areas in Enugu), one witnesses countless number of sidewalk merchants displaying their wares in the open spaces. Others are artisans such as shoe cobblers, vulcanizers, welders, leather and upholstery works in these commercial areas. The sequence of abusive placement of kerosene tanks, metal products for sale, logs of wood, functioning and faulty refrigerators, refuse dumps, abandoned and derelict vehicles and other forms of spatial nuisance along Zik Avenue.

\section{Industrial Land Use}

Emene Industrial Layout, Thinkers Corner, Coal Camp, and Uwani form main industrial areas in Enugu. One observes a number of sidewalk merchants displaying their motor-wares, cars, especially along Zik Avenue.

\section{Recreational Land Use}

Unapproved attachment of illegal structures not contained in the master plan of recreation parks and the indiscriminate erection of lock-up stores in the recreation parks/spaces constitute dysfunctional land use. This is very common in the high density areas as can be evidenced in Osadebe recreation park, Ogui New Layout, Nnaji Recreation Park, New Recreation Park Uwani and Ngwo Recreation Park.

\subsection{Problems of Non-Compliance With Land Use Pattern Traffic congestion}

Umeh (1982) pointed out that traffic is a function of land use activities and as such, the design and operation of traffic and transportation system should be related to rational arrangement of traffic.

Congestion results in delay in movement of goods and services and this has a considerable effect on the workforce. The economic cost of this is in terms of expenditure which comes as the long period spent while traveling from one place to another.

\section{Overcrowding}

The problem of housing is universal even though the degree may vary from country to country (that is, urban areas). This problem will continue to worsen as long as millions of people continue to migrate from the rural areas to the urban areas in search of better employment and better standard of living.

Nigerians, to be precise, the inhabitants of Enugu Urban suffer acute accommodation problem. Most buildings are overcrowded, especially in the low and middle-income earners neighbourhoods. Survey in different parts of Enugu has shown that occupancy rate in some areas are as much as ten (10) persons per room. Even some families subdivided their flats. Others live in ramshackle called shelter. The results of all these problems are increased rent, lack of accommodation, among others. A tenement room is now let for as much as $\$ 4,000.00-\$ 7,000.00$ per month in most parts of Enugu as against $\$ 2,000.00$ - $\$ 4,000.00$ per month few years ago. 3-bedroom bungalows now go for as much as $\$ 350,000.00-\$ 500,000.00$ per annum. This situation has created a distortion in the property market. This arises from the fact that high income earner will because of high rent leave their rightful place of accommodation in low density areas, while those supposed to live in medium density areas will move down to displace income earners in the high density areas which will result to their going elsewhere to look for accommodation, probably in the squalor (slum). This process is called filtering down process in real estates and as such creates a vertical shift in land values. A closer observation will reveal that most of the low cost houses built by the government are being occupied by the middle and high class citizenry. Evidently, the area you occupy may not necessarily be your societal class. This situation is inherent in Enugu urban. 


\section{Methodology}

The study employed survey research design. A total of 133 questionnaires were administered on respondents comprising of 94 registered Estate Surveyors and Valuers practising in Enugu Metropolis and 39 registered Town Planners working in the Enugu State Ministry of Lands and Urban Development. Oral interview was carried out to obtain personal opinions of various professionals. The data collected were analysed using statistical weighted mean.

The formula for mean $=\quad$ Mean $(\mu)=\quad \frac{\sum F x}{N}$

Where $\mu=$ Mean, $\sum=$ Summation, $F=$ Frequency of respondent, $\mathrm{X}=$ Nominal value of option and $\mathrm{N}=$ Total number of respondents.

Nominal values were assigned to different scaling items as follows:

Strongly agree $(\mathrm{SA})=4$ points

$$
\text { Agree (A) }=3 \text { points }
$$

Disagree (D) $\quad=2$ points

Strongly Disagree $(\mathrm{SD}) \quad=1$ point

The cut - off point was determined by summing the nominal value and dividing by the total number of the scaling items thus:

Mean $=\frac{4+3+2+1}{4} \quad \underline{10} \quad=2.5$

To analyse the data, any item or mean score that is equal to or greater than $2.5(=$ or $>2.5)$ was regarded as accepted as an indication of agreement with the opinion item. Items whose mean fell below $2.5(\mathrm{x}<2.5)$ are regarded as rejected as indication of disagreement with the opinion item. The numerous data collected were also assembled and arranged in frequency table.

\section{Data Analysis}

4.1 Respondents' views on the problems of urban land use control in Enugu metropolis.

Table 1: What are the problems of urban land use control in Enugu metropolis?

\begin{tabular}{|l|l|l|l|l|l|l|l|}
\hline \multicolumn{1}{|c|}{ Problems } & SA & \multicolumn{1}{|c|}{ A } & \multicolumn{1}{|c|}{ D } & \multicolumn{1}{|c|}{ SD } & \multicolumn{1}{|c|}{ Number } & \multicolumn{1}{c|}{ Mean } & \multicolumn{1}{c|}{ Remark } \\
\hline Traffic congestion & 23 & 60 & 10 & 7 & 100 & 2.99 & Accepted \\
\hline Environmental pollution & 60 & 23 & 7 & 10 & 100 & 3.33 & Accepted \\
\hline Housing problems & 27 & 53 & 10 & 10 & 100 & 2.97 & Accepted \\
\hline Dysfunctional aspect & 21 & 59 & 15 & 5 & 100 & 2.96 & accepted \\
\hline
\end{tabular}

In Table 1 , all the stated problems of urban land use control have mean scores above 2.5. This shows that the respondents accepted that traffic congestion, environmental pollution, housing problems and dysfunctional aspect are the problems of urban land use control in Enugu metropolis.

4.2 Respondents' views on zoning as an effective strategy for urban land use control in Enugu metropolis. Table 2: Is zoning an effective strategy for urban land use control in Enugu metropolis?

\begin{tabular}{|c|c|c|c|c|c|c|c|}
\hline Items & SA & A & D & SD & Number & Mean & Remark \\
\hline $\begin{array}{c}\text { Zoning is an effective strategy for urban land use control } \\
\text { in Enugu metropolis }\end{array}$ & 53 & 47 & - & - & 100 & 3.53 & Accepted \\
\hline
\end{tabular}

In Table 2, the mean score of 3.53 shows that the respondents accepted that zoning is an effective strategy for urban land use control in Enugu metropolis.

4.3 Respondents' views on the existence of laws and policies that guide the use of land in Enugu metropolis. Table 3: Are there existence of laws and policies that guide the use of land in Enugu metropolis?

\begin{tabular}{|c|c|c|c|c|c|c|c|}
\hline Items & SA & A & D & SD & Number & Mean & Remark \\
\hline $\begin{array}{l}\text { Existence of laws and policies that guide the use of land } \\
\text { in Enugu metropolis. }\end{array}$ & 40 & 60 & - & - & 100 & 3.4 & Accepted \\
\hline
\end{tabular}

In Table 3, the mean score of 3.4 shows that the respondents accepted that laws and policies exist that guide the use of land in Enugu metropolis.

4.4 Respondents' views on the effectiveness of existing laws and policies that guide the use of land in Enugu metropolis.

Table 4: Are the laws and policies that guide the use of land in Enugu metropolis effective?

\begin{tabular}{|c|c|c|c|c|c|c|c|}
\hline Items & SA & A & D & SD & Number & Mean & Remark \\
\hline $\begin{array}{c}\text { Effectiveness of the existing laws and policies that guide } \\
\text { the use of land in Enugu metropolis }\end{array}$ & $\mathbf{1 0}$ & $\mathbf{1 0}$ & $\mathbf{7 0}$ & $\mathbf{1 0}$ & $\mathbf{1 0 0}$ & $\mathbf{2 . 2}$ & Rejected \\
\hline
\end{tabular}


In Table 4, the mean score of 2.2 shows that the respondents rejected the effectiveness of existing laws and policies that guide the use of land in Enugu metropolis.

4.5 Respondents' views on the urban land use control strategies applicable in Enugu metropolis. Table 5: What are the urban land use control strategies applicable in Enugu metropolis?

\begin{tabular}{|l|l|l|l|l|l|l|l|}
\hline Items & SA & A & D & SD & Number & Mean & Remark \\
\hline Zoning & 40 & 50 & 5 & 5 & 100 & 3.25 & Accepted \\
\hline Building codes & 35 & 45 & 15 & 5 & 100 & 3.1 & Accepted \\
\hline Environmental Impact Assessment & 31 & 49 & 10 & 10 & 100 & 3.01 & Accepted \\
\hline Subdivision Regulation & 25 & 40 & 18 & 17 & 100 & 3.73 & Accepted \\
\hline
\end{tabular}

In Table 5, all the stated urban land use control strategies applicable in Enugu metropolis have mean scores above 2.5. This shows that the respondents accepted that Zoning, Building Codes, Environmental Impact Assessment and Subdivision Regulation are the urban land use control strategies applicable in Enugu metropolis.

4.6 Respondents' views on the possibility that land use control and administration problems in Enugu metropolis can be solved.

Table 6: Is there possibility that land use control and administration problems in Enugu metropolis can be solved?

\begin{tabular}{|c|c|c|c|c|c|c|c|}
\hline Item & SA & A & D & SD & Number & Mean & Remark \\
\hline $\begin{array}{c}\text { Possibility that land use control and administration } \\
\text { problems in Enugu metropolis can be solved. }\end{array}$ & 20 & 80 & - & - & 100 & 3.2 & Accepted \\
\hline
\end{tabular}

In Table 6 , the mean score of 3.2 shows that the respondents accepted the possibility that land use control and administration problems in Enugu metropolis can be solved.

4.7 Respondents' views on the solutions to the urban land use control and administration problems in Enugu metropolis.

Table 7: What are the ways of solving urban land use control and administration problems in Enugu metropolis?

\begin{tabular}{|l|c|c|c|c|c|c|c|}
\hline \multicolumn{1}{|c|}{ Solutions } & SA & A & D & SD & Number & Mean & Remark \\
\hline Strict adherence to zoning laws & 70 & 28 & 2 & - & 100 & 3.68 & Accepted \\
\hline Rezoning programs & 20 & 80 & - & - & 100 & 3.2 & Accepted \\
\hline Replanning of Enugu metropolis & 30 & 46 & 14 & 10 & 100 & 2.96 & Accepted \\
\hline $\begin{array}{l}\text { Orientation of the public on the implications of altering } \\
\text { existing planning programs }\end{array}$ & 60 & 20 & 8 & 12 & 100 & 3.28 & Accepted \\
\hline
\end{tabular}

In Table 7, all the stated solutions to the urban land use control and administration problems in Enugu metropolis have mean scores above 2.5. This shows that the respondents accepted that strict adherence to zoning laws, rezoning programs, proper planning of Enugu metropolis and orientation of the public on the implications of altering existing planning programs are solutions to the urban land use control and administration problems in Enugu metropolis

The analysis of the various data collected revealed that urban land use control and administration laws and policies are not completely effective and that has greatly affected various land uses especially those uses that on their own could not compete for space. Enugu metropolis master plan for land use was not followed as it is supposed. This is seen as some of the areas zoned for various public purposes were discovered to be rezoned to other private uses rather than the use which would have been beneficial to the public at large. An example is zoo estate that has been converted to residential use.

From the study, majority of the respondents were of the opinion that though there exist laws and policies that guide development in Enugu metropolis, there is ineffective development control which leads to the loss of aesthetic value and gradual deterioration of the environment and dysfunctional land. This is attributed to improper land allocation for various activities and failure to adhere strictly to laws/policies guiding the allocation of land for various uses.

Moreover, the problems of land use control such as traffic congestion, housing problems and dysfunctional aspect, experienced in Enugu metropolis are as a result of non-adherence to planning laws. These problems are seen in areas like Awkunanaw, Achara Layout, Ogui Road, Uwani, Independence Layout, Abakpa Nike and Emene Industrial Layout. They agreed that though laws and policies exist that guide the use of land in Enugu metropolis, these laws are not completely effective as investors or developers usually influence the existing master plan to suit their interest. That is why one can see commercial activities springing up in an area originally mapped out for residential use as seen in Independence layout and Government Reserved Area. 


\section{Conclusion}

In spite of the importance of land as a point on which the wheel of real estate development rotates, Enugu Urban land use control and administration has not received the utmost attention. The importance of efficient machinery to administer and carryout effectively the land use policies cannot be over emphasized. In as much as one would accept that the inadequacies of urban land use control and administration arise from poor adherence to environment planning, control and administrative bureaucracies, one should not lose sight of the fact that zoning is the most effective urban land use control and administration strategy in Enugu metropolis and it is widely accepted and universally used in most developed countries.

Obviously, the quality of environment and the adjoining development enhance the value of property. In this way zoning either by ensuring compatibility or complementarity of land uses, enhances the value of property.

Nevertheless, the possibility of achieving a co-ordinate and balanced urban development under zoning depends on its administration. This is so because, the use of regulation to control land use promotes compliance and certainty that would not exist if there are no statutory basis for these controls.

\section{Recommendations}

Based on the findings from the study, the following recommendations are advanced; In order to realize the objective of zoning as an instrument of proper urban land use planning, zoning must be accorded its legal and proper place in urban land development and control. The uses permitted must be specifically stated in documentary form, rather than in maps, as such documents must be clearly identified with permitted uses. Hence, Enugu urban land use and administrative agencies must appreciate the importance of zoning as the most common and effective means of implementing land use planning. The state government should embark on comprehensive and comparative urban rezoning programs in some areas like, Achara layout, Abakpa areas, Obiagu, some parts of Asata layout and part of Ogui layout. There is need for the proper planning of Enugu metropolis in a way that some of the public uses like, public schools, government hospitals, police stations, waste dump sites, and army barracks among others would be properly zoned at the appropriate places. In the same vein, zoning ordinance governing Enugu metropolis should be binding on all individuals, such that attempts to go contrary to them will result in serious penalties against the defaulter(s).

Real estate developers should always consult the appropriate authorities in the state for necessary approval of the building/development plans and there should be an Environmental Impact Assessment for any development before embarking on it. This will help to regulate the activities of property developers in Enugu metropolis. Such approval of building plans should be in line with the zoning ordinances.

Finally, there should be a harmonious housing policy and urban land use in order to discourage dysfunctional land use pattern. Part of this implementation will include urban renewal programs and slum clearance in the affected areas.

\section{References}

Adeniyi P.O. and Omojola A. (1999): Land Use land cover change evaluation in Sokoto - Rina Basin of North Western Nigeria based on Archival of the Environment (AARSE) on Geoinformation Technology Applications for Resource and Environmental Management in Africa. Pp 143 - 172.

Alder J. (2018). Development Control. (Modern Legal Studies). https://www.amazon.com>development

Aluko O. E. (2000) "Development Control in Nigeria's New Civil Rule Programme". Journal of the Nigerian Institute of Town Planners. (JNITP) 13, 78 - 88.

Arthur Gallion (1986). The Urban Pattern: City Planning and Design. D. Van Nostrand.

Barlowe, R. (1978). Land Resources Economics. Prentice Hall, USA.

Essein, Godswill A., Miss Amodu and Joseph A. Yacim (2009). "Development Control as a Tool for Sustainable Management of the Federal Capital Territory Abuja". http://www.scribd.com/doc/.20682227.

Eze, M. U. and Alozie, M. C. (2016). Land Rights, Management \& Information. SCOA HERITAGE Nig Ltd. Nigeria.

Federal Government of Nigeria, (1992). The Nigerian Urban and Regional Planning Law, Decree No.88 of 1992 , Abuja.

Federal Ministry of Housing and Urban Development (FMH \& UD). (2003). Sustainable Human Settlements Development: National Urban Strategies. Petral Digital Press, Abuja.

Hodge, Gerrald (2014). Planning Canadian Communities: an introduction to the principles, practice and participants. Toronto: Thomson. pp 338 - 390. ISBN 978 - 0 - 17 - 650982 - 8.

Jiboye, A. P. (2005). Globalization and the Urban Growth Process in Nigeria. In fadare et al editors. Globalization, Culture and Nigerian Built Environment. Faculty of Environmental Design and Management, OAU, Ile-Ife, Nigeria. 2, $342-345$.

Kaltho, J. B. (1985): Structure of the Principal laws the Practice of Urban and Regional Planning in Nigeria. Course paper CP/02/6/85. Zaria: Department of Urban and Regional Planning, Ahmadu Bello University. 
Keeble L. (1968). Principles and Practice of Town and Country Planning. The Estate Gazette limited. London, p. 115.

Lamar, Anika (2015)."Zoning as Taxidermy: Neighbourhood Conservation Districts and the Regulation of Aesthetics". Indiana Law Journal.

Mabogunje A.L. (2003). 'The Inclusive City: Popular empowerment of local government in a rapidly urbanizing Africa'. Journal of the Nigerian Institute of Town Planners, 21 (1): 1 - 17.Memuna 1. (2015). The effectiveness of Development Control in Regulating Urban Housing in Ghana. https://www.researchgate.net>publication.

Nze, I. (1995). "Development Control. Matters Arising in the 4th Republic". Paper Presented at the 30th Annual Conference of the NITP held in Akure, Ondo State.

Oyesiku O.O. (1998). Modern Urban Regional Planning Law and Administration in Nigeria. University of Ibadan: Kraft Books Limited.

Ratcliff, J. (2018). An Introduction to Town and Country Planning - Hutching Honden, Melbourne. P.42.

Ratcliff, J. (1976); Land Policy: An Exploration of the Nature of Land in the Society: The Built Environment. 127.

Smith and Engel (2006). Theoretical and Empirical Researches in Urban Management.

United Nations (2000): "Measuring Sustainable Development" . "Report of the Joint UNECE/OECD/Eurostat Working Group on Statistics for Sustainable Development", New York and Geneva.

Vagale J. (1979). Development Control in Adamawa State - IOSR Journal.https://www.iosrjournals.org>papers.

Yemi, O. (2004). Problems and Prospects of Development Control. Paper presented at the 2004 Annual Delegates Conference of the Nigerian Bar Association. Holding at the International Conference Centre, Abuja. 22 to 27 August, 2004. 